\title{
Risk factors for recurrent tuberculosis after successful treatment in a high burden setting: a cohort study
}

\author{
Patrick George Tobias Cudahy ${ }^{1,2^{*}}$, Douglas Wilson ${ }^{2^{*}}$ and Ted Cohen ${ }^{3}$
}

\begin{abstract}
Background: People successfully completing treatment for tuberculosis remain at elevated risk for recurrent disease, either from relapse or reinfection. Identifying risk factors for recurrent tuberculosis may help target posttuberculosis screening and care.

Methods: We enrolled 500 patients with smear-positive pulmonary tuberculosis in South Africa and collected baseline data on demographics, clinical presentation and sputum mycobacterial cultures for 24-loci mycobacterial interspersed repetitive unit-variable number tandem repeat (MIRU-VNTR) typing. We used routinely-collected administrative data to identify recurrent episodes of tuberculosis occurring over a median of six years after successful treatment completion.

Results: Of 500 patients initially enrolled, 333 (79\%) successfully completed treatment for tuberculosis. During the follow-up period 35 patients with successful treatment (11\%) experienced a bacteriologically confirmed tuberculosis recurrence. In our Cox proportional hazards model, a 3+ AFB sputum smear grade was significantly associated with recurrent tuberculosis with a hazard ratio of 3.33 (95\% Cl 1.44-7.7). The presence of polyclonal M. tuberculosis infection at baseline had a hazard ratio for recurrence of 1.96 (95\% Cl 0.86-4.48).

Conclusion: Our results indicate that AFB smear grade is independently associated with tuberculosis recurrence after successful treatment for an initial episode while the association between polyclonal M. tuberculosis infection and increased risk of recurrence appears possible.
\end{abstract}

Keywords: Mixed-infection, South Africa, Relapse, Reinfection, Fuzzy match

\section{Introduction}

Patients who have recently completed treatment for tuberculosis (TB) are at elevated risk of recurrent $\mathrm{TB}$ disease, either as a result of relapse or reinfection $[1,2]$. When individuals are diagnosed with recurrent TB, they are less likely to complete treatment and suffer higher

\footnotetext{
* Correspondence: patrick.cudahy@yale.edu; wilsondpk@gmail.com 'Section of Infectious Disease, Department of Medicine, Yale University School of Medicine, New Haven, CT, USA

${ }^{2}$ Department of Internal Medicine, Edendale Hospital, University of

KwaZulu-Natal, 5th Floor, Private Bag X 509, Plessislaer, KZN, Pietermaritzburg 3216, South Africa

Full list of author information is available at the end of the article
}

mortality than those with first episodes of TB [3]. While there is a growing appreciation of the risks associated with recurrent $\mathrm{TB}$, a clearer picture of which covariates place individuals at greater risk of recurrent disease can inform more targeted post-tuberculosis care and monitoring.

Several covariates have been found to be associated with recurrence of $\mathrm{TB}$ after completion of treatment. Drug-resistance [4], smoking [5], HIV infection with low CD4 lymphocyte counts [6], substance use [7], chronic lung disease [8], sputum smear-positive disease [9], and cavitary pulmonary disease [10] have each been found to

C C The Author(s). 2020 Open Access This article is licensed under a Creative Commons Attribution 4.0 International License, which permits use, sharing, adaptation, distribution and reproduction in any medium or format, as long as you give appropriate credit to the original author(s) and the source, provide a link to the Creative Commons licence, and indicate if changes were made. The images or other third party material in this article are included in the article's Creative Commons licence, unless indicated otherwise in a credit line to the material. If material is not included in the article's Creative Commons licence and your intended use is not permitted by statutory regulation or exceeds the permitted use, you will need to obtain permission directly from the copyright holder. To view a copy of this licence, visit http://creativecommons.org/licenses/by/4.0/ The Creative Commons Public Domain Dedication waiver (http://creativecommons.org/publicdomain/zero/1.0/) applies to the data made available in this article, unless otherwise stated in a credit line to the data. 
be associated with increased risk of recurrent tuberculosis. These factors may increase risk of recurrence because they make it more likely for some small numbers of mycobacteria to persist beyond treatment or because they are associated with immune incompetence that places individuals at greater risk of disease following reinfection [11].

Over the last few years, molecular genetic tools have provided a new view on the extent of within-host genotypic heterogeneity of Mycobacterium tuberculosis infections. These "mixed-strain" or "heterogeneous" infections arise either through sporadic mutation (clonal heterogeneity) or host acquisition of more than one strain of $M$. tuberculosis (polyclonal heterogeneity), either at the time of infection or through serial reinfection [12]. While detection of mixed-strain infection is limited by the biological samples collected as well as the laboratory processes and sensitivity of sequencing, the frequency at which clonal heterogeneity and polyclonal heterogeneity are reported is nearly $20 \%$ in some settings [13]. While several studies have found that within-host heterogeneity, especially polyclonal infections, are associated with poorer treatment response [14], the effects on risk of recurrence are less clear [13].

Studies of recurrent $\mathrm{TB}$ are challenging to conduct because the risk of recurrent TB can remain elevated for up to ten years [2]. In this analysis, we combined a research database with electronic notification records to study the long term risk of recurrent tuberculosis among a cohort of ambulatory pulmonary TB patients with a high prevalence of HIV co-infection after successful completion of anti-tubercular therapy.

\section{Methods}

\section{Setting}

The Umgungundlovu health district, in KwaZulu-Natal (KZN), South Africa had a tuberculosis notification rate of 880 cases per 100,000 during the initial study period of 2011. Local HIV prevalence was $16.9 \%$ and approximately $70 \%$ of people with active tuberculosis were coinfected with HIV [15].

\section{Participants}

All adults with newly diagnosed pulmonary tuberculosis and sputum smear-positive for acid-fast bacilli (AFB) from five primary health care clinics in the Umgungundlovu health district were eligible for the study. Between June 2011 and November 2012 we enrolled 500 participants and collected two spot pre-treatment sputum samples. Immediately after enrollment, participants were initiated on antitubercular therapy according to South African Department of Health guidelines. Further details of study design are available in a previous publication [16].

\section{Laboratory}

Pre-treatment sputum samples were cultured and those positive for $M$. tuberculosis were genotyped with 24-loci mycobacterial interspersed repetitive unit-variable number tandem repeat (MIRU-VNTR) typing at Genoscreen (Institute Pasteur, Lille, France) [17]. Details of the laboratory procedures have been published previously [16]. For samples with multiple repeats at any MIRUVNTR loci, indicating more than genotype, the ClassTR algorithm [18] was used to distinguish clonal M. tuberculosis infection from polyclonal $M$. tuberculosis infection.

\section{Follow-up}

After completion of antitubercular therapy, we tracked outcomes by using routinely collected electronic treatment register (ETR) [19] data. The Umgungundlovu health district ETR data includes 50 clinics serving a population of over 1,000,000 people, and also encompasses the original 5 sites from which participants were recruited [20]. Each facility in the district records tuberculosis case information, including final treatment outcome, in a standardized paper tuberculosis register. The health district collects local facility tuberculosis registers and enters them into a district-wide ETR.

We matched study participants with district data in ETR by exact matching of identifiers (e.g. name, gender, date of birth, treatment start date). As there is no unique patient identifier in South Africa and there are several opportunities during administrative data collection for transcription errors, we conducted fuzzy matching for study participants not located by exact matching. We allowed for substitutions of numerical variables and used Jaro-Winkler [21] distance for matching string variables. A study author (PC) reviewed all potential matches. We recorded the final treatment outcome for each participant. For participants who the ETR listed as lost to follow-up or who transferred their care during treatment, further exact and fuzzy searches were made to attempt to link care episodes and establish a final treatment outcome.

For study participants with documented treatment success (by World Health Organization defined [22] cure or treatment completion) of their initial episode of tuberculosis, a search for secondary episodes of tuberculosis was then made in the electronic register during the period from initial study enrollment though March 30, 2019. For any secondary tuberculosis episodes found in the electronic register, we recorded the time to recurrence from the initial diagnosis as well as the method of tuberculosis diagnosis (empiric, smear microscopy, Gene Xpert MTB/Rif, or culture), and treating clinic.

We constructed Cox proportional hazards models with an outcome of recurrent tuberculosis. Participants were 
censored on the date the ETR search was made. For a multivariable model, we included covariates for withinhost $M$. tuberculosis heterogeneity (simple, clonal, and polyclonal) as this was the focus of the study as well as HIV status, given its strong association with recurrent tuberculosis, and a gaussian frailty random effects term for the health center to adjust for clustering. In addition, covariates with a $p$-value of $<0.20$ (age, education, marital status, and AFB sputum smear grade) in univariable models were included.

\section{Statistical analysis}

$\mathrm{R}$ statistical software was used to perform statistical analyses [23]. Cox proportional hazard models were constructed using the packages survival [24] version 2.42-6, survminer [25] version 0.4.3, and prodlim [26] version 2018.04.18 to assess whether any factors were associated with recurrent tuberculosis after treatment completion for the initial episode. Proportionality was assessed with correlations between Schoenfeld residuals and log (time) for each covariate and the global model. Multicollinearity was assessed using variance inflation factor.

\section{Results}

During the study enrollment and follow-up period, 110, 859 cases of tuberculosis were recorded in the Umgungundlovu Health District ETR. Of the 500 patients initially enrolled, we matched 478 (96\%) within the ETR (Fig. 1). 135 (28\%) had a treatment outcome of "not evaluated" due to clinic transfer or loss to followup. Further searches allowed discovery of the treating clinic of 89 of these $135(66 \%)$ to determine a final treatment outcome. $421(88 \%)$ of the matched participants had a positive baseline mycobacterial culture with successful MIRU-VNTR genotyping.

333 (79\%) of the original study participants with a MIRU-VNTR genotype were recorded as achieving treatment completion or cure for their initial tuberculosis episode (Table 1). Those with a successful treatment outcome were less likely to be living with HIV (65.8 vs 79\%) and less likely to have sputum negative for AFB (40.8\% vs 56.3\%) (Supplemental Table 1). In this cohort, median age was 35 years, and $57 \%$ were men. 228 (69\%) were HIV positive and 77 (23\%) had evidence of heterogeneous $M$. tuberculosis infection by MIRUVNTR genotyping. When utilizing the ClassTR algorithm to interpret MIRU-VNTR results, 30 (9\%) had clonally heterogeneous $M$. tuberculosis disease, and 47 (14\%) had polyclonal heterogeneous $M$. tuberculosis disease. 59 (18\%) had a history of tuberculosis prior to enrollment. 7 (2\%) had multidrug-resistant TB (MDR-TB).

The time from initial tuberculosis diagnosis to searching in the District ETR was a median of 2125 days (interquartile range 2032 to 2271 days). Fourty-five participants (14\%) were diagnosed with recurrent tuberculosis, of which 35 participants (11\%) had bacteriologically proven tuberculosis, by either sputum smear, Gene Xpert, or culture, after a median of 504 days. KaplanMeier curves for bacteriologically proven recurrent tuberculosis after treatment for either simple, clonal or polyclonal $M$. tuberculosis tuberculosis infection were not statistically significantly different by log-rank test (Fig. 2).

In univariable analysis with Cox proportional hazards models, younger age was significantly associated with increased risk of bacteriologically proven tuberculosis

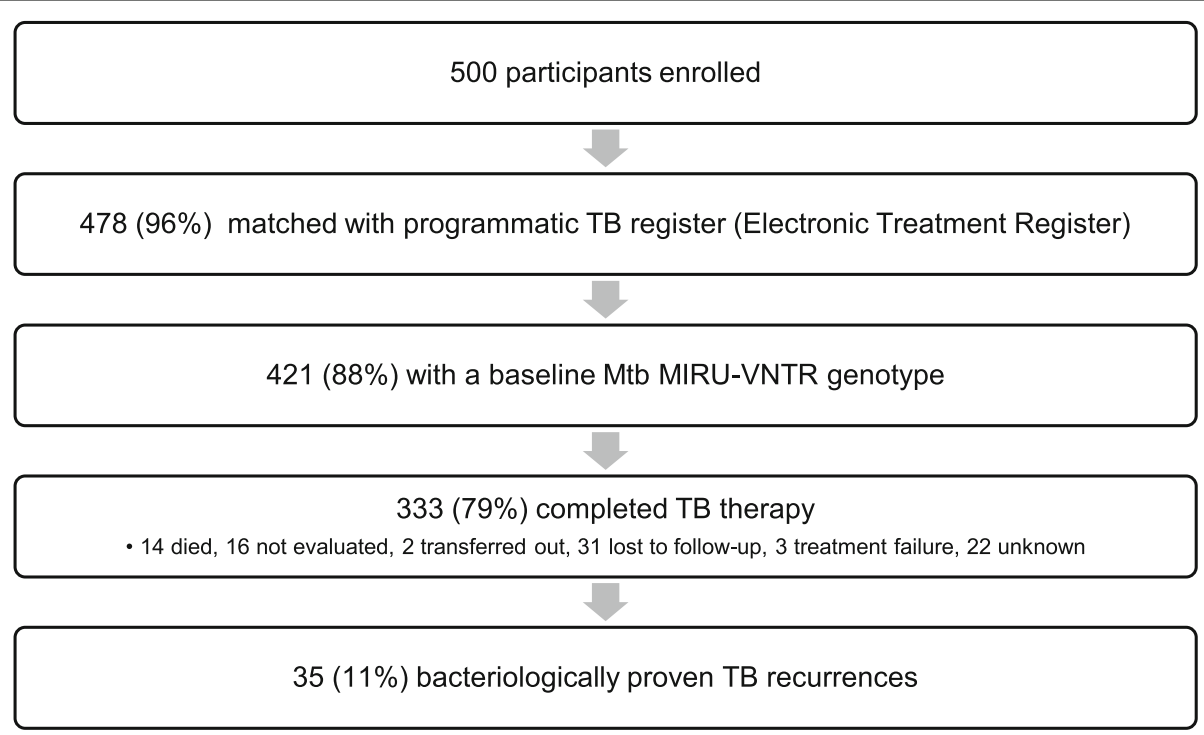

Fig. 1 Participant flow diagram 
Table 1 Baseline characteristics

\begin{tabular}{|c|c|c|}
\hline \multirow[t]{2}{*}{$\mathbf{n}$} & No recurrent tuberculosis & Recurrent tuberculosis \\
\hline & 298 & 35 \\
\hline Age in years (mean (SD)) & $35.31(11.36)$ & $30.03(8.55)$ \\
\hline Male gender (\%) & $170(57.0)$ & $21(60.0)$ \\
\hline Married (\%) & $46(15.4)$ & $2(5.7)$ \\
\hline Education in years (\%) & $9.54(2.63)$ & $9.59(2.77)$ \\
\hline History of imprisonment (\%) & $18(6.0)$ & $4(11.4)$ \\
\hline Diabetes (\%) & $7(2.3)$ & $2(5.7)$ \\
\hline HIV (\%) & $206(69.1)$ & $22(62.9)$ \\
\hline Previous treatment for tuberculosis (\%) & $54(18.1)$ & $4(11.4)$ \\
\hline \multicolumn{3}{|l|}{ Sputum AFB smear grade } \\
\hline Scanty (\%) & $21(7.0)$ & $2(5.7)$ \\
\hline $1+(\%)$ & $69(23.2)$ & $6(17.1)$ \\
\hline $2+(\%)$ & $34(11.4)$ & $4(11.4)$ \\
\hline $3+(\%)$ & $48(16.1)$ & $13(37.1)$ \\
\hline Clonal mixed TB infection (\%) & $27(9.1)$ & $3(8.6)$ \\
\hline Polyclonal mixed TB infection (\%) & $39(13.1)$ & $8(22.9)$ \\
\hline
\end{tabular}

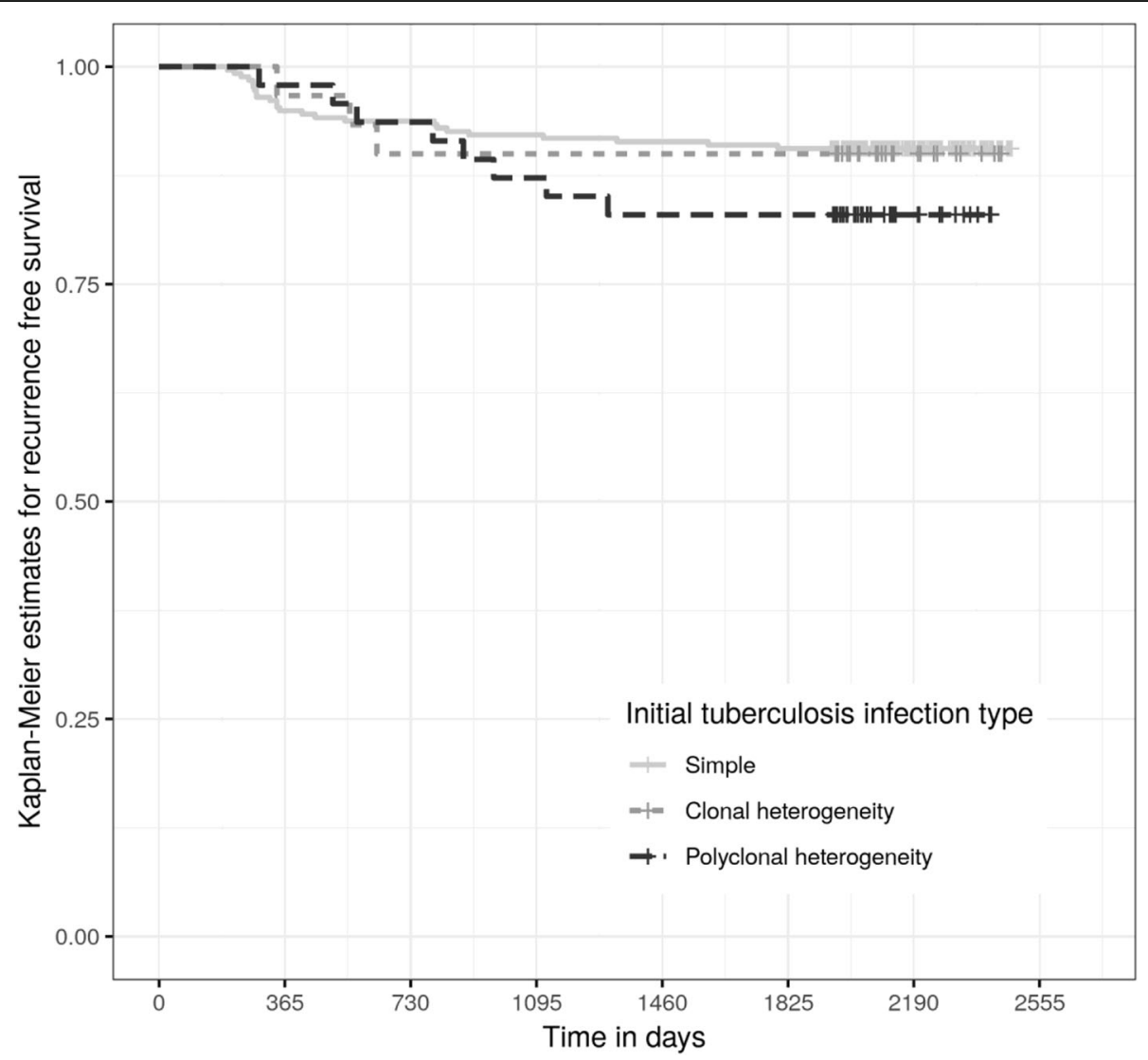

Fig. 2 Kaplan Meier estimates for freedom from recurrent tuberculosis after completion or cure 
recurrence with a hazard ratio of 0.94 (95\% confidence interval (CI) 0.91-0.98) for every additional year of age (Table 2). In our multivariable model, a 3+ AFB sputum smear grade was significantly associated with recurrent tuberculosis with a hazard ratio of 3.33 (95\% CI 1.447.7, $p=0.005$ ) (Fig. 3). The presence of clonally heterogeneous $M$. tuberculosis infection at baseline had a hazard ratio for recurrence of 0.92 (95\% CI 0.27-3.1), while polyclonal heterogeneous $M$. tuberculosis infection at baseline had a hazard ratio for recurrence of 1.96 (95\% CI 0.86-4.5). None of those with recurrent tuberculosis had MDR-TB at baseline, which made inclusion of MDR-TB in our models impossible.

\section{Discussion}

After following a cohort of largely HIV-coinfected ambulatory individuals successfully treated for pulmonary tuberculosis disease in a high burden setting for a median of 6 years, we found that $11 \%$ (95\% CI 7.2 to $13.8 \%$ ) had bacteriologically proven recurrent tuberculosis and an additional 3\% (95\% CI 1.2 to $4.8 \%$ ) had empiricallydiagnosed recurrent tuberculosis. This is consistent with other studies performed in high burden settings [2, 27].

Our finding of an association between higher sputum AFB smear grade during the initial tuberculosis episode and recurrent episodes of tuberculosis may be due higher mycobacterial load disease and cavitary disease, leading to a higher risk of relapse after treatment completion. The association between smear grade and poor treatment outcomes, including recurrent disease, has been seen in other studies [28].
In this long-term follow-up, the point estimate for the odds of recurrence for individuals with polyclonal $M$. tuberculosis infection was 1.96, but the 95\% confidence interval did not exclude 1 . The relatively small number of outcomes recorded limits our ability to make conclusive statements about whether such polyclonal infections make it more likely for patients to experience relapse after successful treatment. An association of recurrent tuberculosis and heterogeneous $M$. tuberculosis infection is plausible as heterogeneous infection leads to the potential for heteroresistance. Additionally, Shin and colleagues recently found an association between heterogeneous $M$. tuberculosis infection and treatment failure in Botswana that was independent of heteroresistance [14]. A high mycobacterial burden within a host or repeated exposures to tuberculosis in a high TB prevalence environment could be other mechanisms for an association of heterogeneous $M$. tuberculosis infection and poor treatment outcomes or recurrence.

HIV co-infection was not associated with the risk of recurrence in univariable or multivariable analysis. This could reflect rising rates of antiretroviral therapy in our setting, and that South African guidelines at the time of our initial study recommended placing patients living with HIV and tuberculosis co-infection on antiretrovirals. Antiretrovirals reduce the risk of developing active tuberculosis, but how that risk compares to the HIV uninfected population is not currently known $[6,29,30]$. Alternatively, participants living with HIV could have suffered higher mortality rates in subsequent years that may have biased our results given we did not have access to vital statistics.

Table 2 Unadjusted and adjusted hazard ratios for recurrent tuberculosis

\begin{tabular}{|c|c|c|c|c|c|c|}
\hline $\mathbf{n}$ & $\begin{array}{l}\text { Unadjusted hazard } \\
\text { ratio for recurrent } \\
\text { tuberculosis }\end{array}$ & $\begin{array}{l}\text { 95\% Confidence } \\
\text { interval }\end{array}$ & $p$-value & $\begin{array}{l}\text { Adjusted hazard } \\
\text { ratio for recurrent } \\
\text { tuberculosis }\end{array}$ & $\begin{array}{l}95 \% \text { Confidence } \\
\text { interval }\end{array}$ & p-value \\
\hline Age in years & 0.95 & $0.91-0.99$ & $<0.01$ & 0.91 & $0.04-1.00$ & $<0.01$ \\
\hline Male gender & 1.13 & $0.57-2.22$ & 0.71 & & & \\
\hline Married & 0.34 & $0.08-1.45$ & 0.14 & 0.75 & $0.16-3.59$ & 0.72 \\
\hline Education in years & 1.20 & $0.99-1.48$ & 0.06 & 1.09 & $0.89-1.33$ & 0.40 \\
\hline History of imprisonment & 1.92 & $0.68-5.46$ & 0.22 & & & \\
\hline Diabetes & 2.34 & $0.56-9.77$ & 0.24 & & & \\
\hline HIV & 0.77 & $0.39-1.53$ & 0.46 & 0.99 & $0.48-2.05$ & 0.99 \\
\hline Previous treatment for tuberculosis & 0.59 & $0.20-1.67$ & 0.32 & & & \\
\hline \multicolumn{7}{|l|}{ Sputum AFB smear grade } \\
\hline Scanty & 1.16 & $0.26-5.33$ & 0.84 & 1.36 & $0.29-6.35$ & 0.70 \\
\hline $1+$ & 1.12 & $0.41-3.10$ & 0.82 & 1.10 & $0.39-3.10$ & 0.85 \\
\hline $2+$ & 1.47 & $0.46-4.71$ & 0.51 & 1.29 & $0.40-4.20$ & 0.67 \\
\hline $3+$ & 3.14 & $1.38-7.19$ & $<0.01$ & 3.33 & $1.44-7.70$ & $<0.01$ \\
\hline Clonal mixed TB infection & 1.06 & $0.32-3.53$ & 0.92 & 0.92 & $0.27-3.12$ & 0.90 \\
\hline Polyclonal mixed TB infection & 1.82 & $0.82-3.99$ & 0.14 & 1.96 & $0.86-4.48$ & 0.11 \\
\hline
\end{tabular}




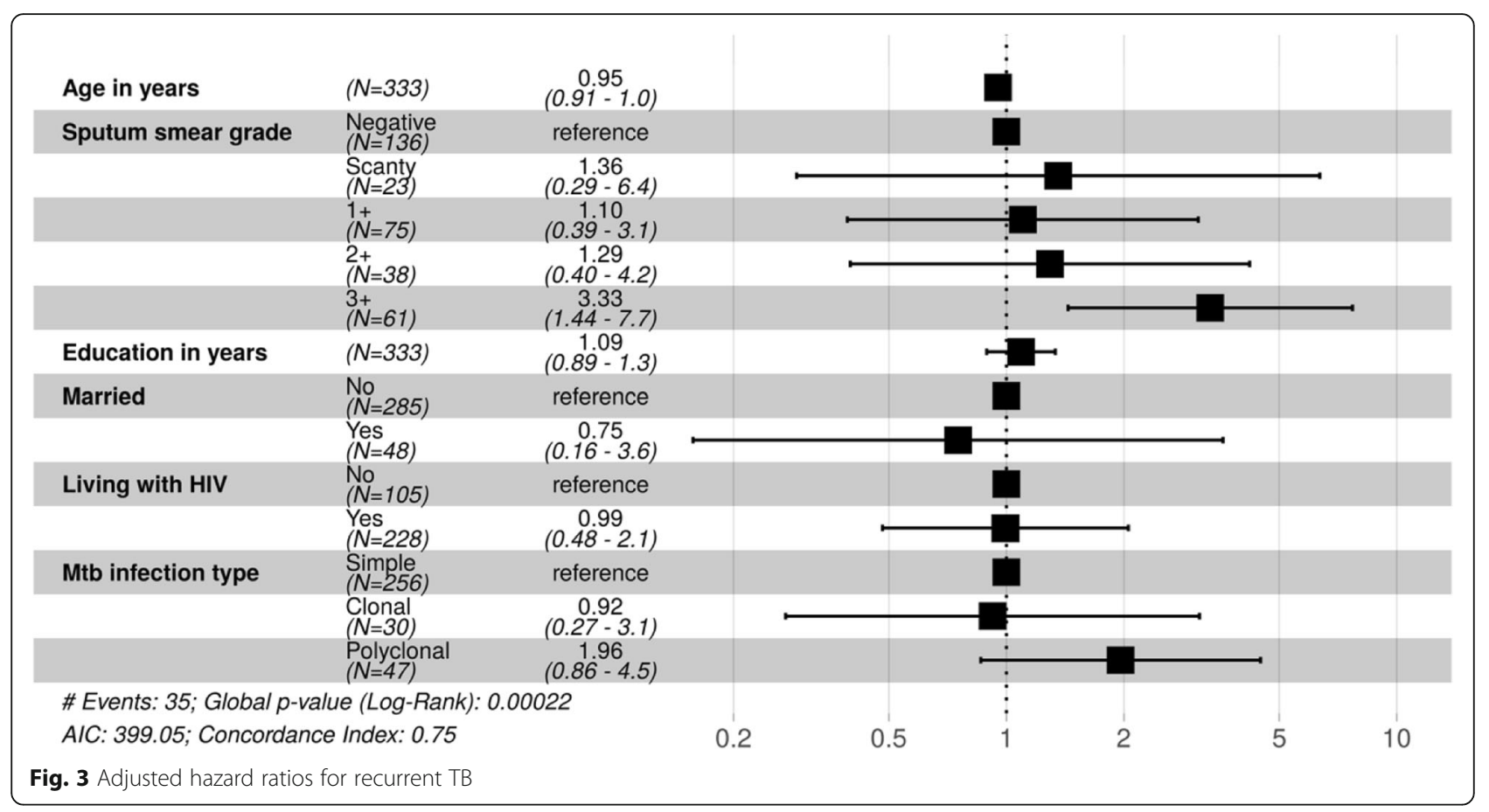

There were limitations in linking our study dataset with ETR data to identify recurrent tuberculosis episodes as there is currently no national health identifier in South Africa. Fuzzy matching of patient identifiers identified many instances of likely matches that were initially missed due to misspellings and transpositions, but we do not know if other matches were missed due to larger discrepancies and whether this introduced bias into our findings. If risk factors of recurrence are also associated with death, lack of access to vital statistics may have biased results by not properly censoring participants who died during the follow-up period.

This limitation leads to our finding of $11 \%$ recurrence as a lower bound on the burden of recurrent tuberculosis. Additionally, even though the ETR encompasses a health district that serves over 1,000,000 people, the population of KZN is highly mobile [31] and the ETR database does not capture recurrences outside of the health district. 135 (28\%) of the participants in this study transferred clinics or were lost to follow-up during their initial TB treatment and we were able to locate $66 \%$ of them at their final treating clinic within the health district. It is conceivable that migration out of the health district may have introduced some bias into our study.

Another limitation is that our sampling was at one timepoint from one anatomical source (sputum). Our group's work with post-mortem studies in the same population as represented in this study has found significant proportions of multi-organ disseminated tuberculosis with strain heterogeneity that was not captured when sampling sputum alone [32]. Genotyping with
MIRU-VNTR also has limited sensitivity for determining M. tuberculosis strain diversity and may have underestimated the true proportion of heterogeneous infection [12]. We also were unable to genotype $M$. tuberculosis strains from recurrent episodes to distinguish reinfection from relapse. In other studies with matched fingerprinting of initial and recurrent tuberculosis episodes, reinfection accounted for at least half of recurrent disease, reflecting the hyperendemic communities to which people living with tuberculosis return to after treatment completion. We suspect similarly high rates of reinfection occurred in our population as well, but we do not have genotypes from recurrent tuberculosis episodes to test this hypothesis.

\section{Conclusions}

Our results indicate that AFB smear grade is independently associated with tuberculosis recurrence after successful treatment for an initial episode while the association between polyclonal $M$. tuberculosis infection and increased risk of recurrence appears possible, but further studies are needed to better establish this relationship.

\section{Supplementary information}

Supplementary information accompanies this paper at https://doi.org/10. 1186/s12879-020-05515-4.

Additional file 1: Supplemental Table 1. Comparison of participants enrolled but not included in the final analysis vs those included in the final analysis. 


\section{Abbreviations}

AFB: Acid-fast bacilli; Cl: Confidence interval; ETR: Electronic treatment register; KZN: KwaZulu-Natal; MDR-TB: Multidrug-resistant tuberculosis; MIRUVNTR: Mycobacterial interspersed repetitive unit-variable number tandem repeat; TB: Tuberculosis

\section{Acknowledgements}

We wish to thank the KwaZulu-Natal Department of Health and its TB Director, Ms. Jacqueline Ngozo for their assistance with this study. We also wish to thank the nursing staff and management at the Umgungundlovu District primary healthcare clinics.

\section{Authors' contributions}

PGTC, TC and DW conceived of and deigned this study. PGTC conducted the data analysis. All authors contributed to manuscript preparation and approval of the final version.

\section{Funding}

This work was supported by the Fogarty International Center [grant number 1K01TW011194-01A1 to P.G.T.C] at the National Institutes of Health and a fellowship from the Burroughs Wellcome Fund/American Society of Tropical Medicine and Hygiene Postdoctoral Fellowship in Tropical Infectious Diseases to P.G.T.C. The funders had no role in study design, data collection and analysis, decision to publish, or preparation of the manuscript.

\section{Availability of data and materials}

The data sets compiled and analyzed for the current study are available from the corresponding author on reasonable request.

\section{Ethics approval and consent to participate}

The Biomedical Research Ethics Committee at the University of KwaZuluNatal and the KwaZulu-Natal Department of Health, as well as the Partners Human Research Committee (Boston, Massachusetts), approved the protocol for the original study. The University of KwaZulu-Natal's Biomedical Research Ethics Committee, the KwaZulu-Natal Department of Health, and the Yale University Human Investigations Committee approved the additional use of ETR data for this analysis. Written informed consent was obtained from all participants.

\section{Consent for publication}

Not applicable.

\section{Competing interests}

The authors declare that they have no competing interests.

\section{Author details}

${ }^{1}$ Section of Infectious Disease, Department of Medicine, Yale University School of Medicine, New Haven, CT, USA. ${ }^{2}$ Department of Internal Medicine, Edendale Hospital, University of KwaZulu-Natal, 5th Floor, Private Bag X 509 , Plessislaer, KZN, Pietermaritzburg 3216, South Africa. ${ }^{3}$ Department of Epidemiology (Microbial Diseases), Yale University School of Public Health, New Haven, CT, USA.

\section{Received: 13 May 2020 Accepted: 15 October 2020}

Published online: 23 October 2020

\section{References}

1. Marx FM, Floyd S, Ayles H, Godfrey-Faussett P, Beyers N, Cohen T. High burden of prevalent tuberculosis among previously treated people in southern Africa suggests potential for targeted control interventions. Eur Respir J. 2016;48(4):1227-30.

2. Uys P, Brand H, Warren $R$, van der Spuy G, Hoal EG, van Helden PD. The risk of tuberculosis reinfection soon after cure of a first disease episode is extremely high in a Hyperendemic community. PLoS One. 2015;10(12): e0144487

3. Murray J, Sonnenberg P, Shearer SC, Godfrey-Faussett P. Human immunodeficiency virus and the outcome of treatment for new and recurrent pulmonary tuberculosis in African patients. Am J Respir Crit Care Med. 1999;159(3):733-40.
4. Sun $Y$, Harley D, Vally $H$, Sleigh A. Impact of multidrug resistance on tuberculosis recurrence and long-term outcome in China. PLoS One. 2017; 12(1): e0168865. https://doi.org/10.1371/journal.pone.0168865.

5. Yen $Y-F$, Yen M-Y, Lin Y-S, Lin Y-P, Shih H-C, Li L-H, et al. Smoking increases risk of recurrence after successful anti-tuberculosis treatment: a populationbased study. Int J Tuberc Lung Dis. 2014;18(4):492-8.

6. Golub JE, Durovni B, King BS, Cavalacante SC, Pacheco AG, Moulton LH, et al. Recurrent tuberculosis in HIV-infected patients in Rio de Janeiro. Brazil AIDS Lond Engl. 2008;22(18):2527-33.

7. Kim L, Moonan PK, Heilig CM, Yelk Woodruff RS, Kammerer JS, Haddad MB. Factors associated with recurrent tuberculosis more than 12 months after treatment completion. Int J Tuberc Lung Dis Off J Int Union Tuberc Lung Dis. 2016:20(1):49-56.

8. Pettit AC, Kaltenbach LA, Maruri F, Cummins J, Smith TR, Warkentin JV, et al. Chronic lung disease and HIV infection are risk factors for recurrent tuberculosis in a low-incidence setting. Int J Tuberc Lung Dis Off J Int Union Tuberc Lung Dis. 2011;15(7):906-11.

9. Pascopella L, DeRiemer K, Watt JP, Flood JM. When Tuberculosis Comes Back: Who Develops Recurrent Tuberculosis in California? PLoS One. 2011; 6(11): e26541. https://doi.org/10.1371/journal.pone.0026541.

10. Sonnenberg P, Murray J, Glynn JR, Shearer S, Kambashi B, Godfrey-Faussett P. HIV-1 and recurrence, relapse, and reinfection of tuberculosis after cure: a cohort study in south African mineworkers. Lancet. 2001;358(9294):1687-93.

11. Mirsaeidi M, Sadikot R. Patients at high risk of tuberculosis recurrence. Int J Mycobacteriology. 2018;7(1):1-6.

12. Cohen T, van Helden PD, Wilson D, Colijn C, McLaughlin MM, Abubakar I, et al. Mixed-strain mycobacterium tuberculosis infections and the implications for tuberculosis treatment and control. Clin Microbiol Rev. 2012;25(4):708-19.

13. Mclvor A, Koornhof H, Kana BD. Relapse, re-infection and mixed infections in tuberculosis disease. Pathog Dis. 2017;75(3) Available from: https:// academic.oup.com/femspd/article/75/3/ftx020/3003284. [cited 2018 Oct 19].

14. Shin SS, Modongo C, Baik Y, Allender C, Lemmer D, Colman RE, et al. Mixed Mycobacterium tuberculosis-Strain Infections Are Associated With Poor Treatment Outcomes Among Patients With Newly Diagnosed Tuberculosis, Independent of Pretreatment Heteroresistance. J Infect Dis. 2018; [cited 2018 Oct 19]. https://doi.org/10.1093/infdis/jiy480/5066433.

15. Massyn N, Day C, Dombo M, Barron P, English R, Padarath A. District health barometer 2012/13 [internet]. Health Systems Trust: Durban; 2013. Available from: http://www.hst.org.za/publications/District\%20Health\%20Barometers/ CompleteDHB2012-2013.pdf.

16. Cohen T, Chindelevitch L, Misra R, Kempner ME, Galea J, Moodley P, et al. Within-host heterogeneity of M. tuberculosis infection is associated with poor early treatment response: a prospective cohort study. J Infect Dis. 2016;213(11):1796-9.

17. Oelemann MC, Diel R, Vatin V, Haas W, Rüsch-Gerdes S, Locht C, et al. Assessment of an optimized mycobacterial interspersed repetitive- unitvariable-number tandem-repeat typing system combined with Spoligotyping for population-based molecular epidemiology studies of tuberculosis. J Clin Microbiol. 2007;45(3):691-7.

18. Chindelevitch L, Colijn C, Moodley P, Wilson D, Cohen T. ClassTR: classifying within-host heterogeneity based on tandem repeats with application to mycobacterium tuberculosis infections. PLoS Comput Biol. 2016 Feb 1;12(2): e1004475.

19. ETR.Net - Country Implementations [Internet]. 2007 [cited 2020 Feb 24]. Available from: http://www.etrnet.info/Countrylmplementations.aspx.

20. Department of Health. Umgungundlovu Health District: Annual Report 2017/18 [Internet]. 2018 [cited 2018 Oct 12]. Available from: www.kznhealth. gov.za/2017-2018-Annual-Report.pdf.

21. Winkler WE, Thibaudeau Y. An Application of the Fellegi-Sunter Model of Record Linkage to the 1990 U.S. Decennial Census; Technical report, US Bureau of the Census; 1987. p. 22. Report No.: RR91-09.

22. World Health Organization. Global Tuberculosis Report 2019. Geneva; 2019. Report No:: WHO/CDS/TB/2019.15.

23. R Core Team. R: a language and environment for statistical computing. Vienna: R Foundation for Statistical Computing; 2019. Available from: https://www.R-project.org.

24. Therneau TM. A package for survival analysis in S [internet]. 2015. Available from: https://www.CRAN.R-project.org/package=survival.

25. Kassambara A, Kosinski M. survminer: Survival Analysis and Visualization [Internet]. [cited 2018 Nov 29]. Available from: https://www.rpkgs.datanovia. com/survminer/index.html. 
26. Gerds TA. prodlim: Product-Limit Estimation for Censored Event History Analysis [Internet]. 2018 [cited 2018 Nov 30]. Available from: https://www. CRAN.R-project.org/package= prodlim.

27. Marx FM, Dunbar R, Enarson DA, Williams BG, Warren RM, van der Spuy GD, et al. The temporal dynamics of relapse and reinfection tuberculosis after successful treatment: a retrospective cohort study. Clin Infect Dis. 2014; 58(12):1676-83.

28. Imperial MZ, Nahid P, Phillips PPJ, Davies GR, Fielding K, Hanna D, et al. A patient-level pooled analysis of treatment-shortening regimens for drugsusceptible pulmonary tuberculosis. Nat Med. 2018;24(11):1708.

29. Van Rie A, Westreich D, Sanne I. Tuberculosis in patients receiving antiretroviral treatment: incidence, risk factors and prevention strategies. J Acquir Immune Defic Syndr 1999. 2011;56(4):349-55.

30. Bock P, Jennings K, Vermaak R, Cox H, Meintjes G, Fatti G, et al. Incidence of tuberculosis among HIV positive individuals initiating antiretroviral treatment at higher CD4 counts in the HPTN 071 (PopART) trial in South Africa. J Acquir Immune Defic Syndr. 2018;77(1):93-101.

31. Camlin CS, Snow RC, Hosegood V. Gendered patterns of migration in rural South Africa. Popul Space Place. 2014;20(6):528-51.

32. Lieberman TD, Wilson D, Misra R, Xiong LL, Moodley P, Cohen T, et al. Genomic diversity in autopsy samples reveals within-host dissemination of HIV-associated mycobacterium tuberculosis. Nat Med. 2016;22(12):1470-4.

\section{Publisher's Note}

Springer Nature remains neutral with regard to jurisdictional claims in published maps and institutional affiliations.

Ready to submit your research? Choose BMC and benefit from:

- fast, convenient online submission

- thorough peer review by experienced researchers in your field

- rapid publication on acceptance

- support for research data, including large and complex data types

- gold Open Access which fosters wider collaboration and increased citations

- maximum visibility for your research: over $100 \mathrm{M}$ website views per year

At BMC, research is always in progress.

Learn more biomedcentral.com/submissions 